E3 Journal of Agricultural Research and Development Vol. 6(3). pp. 056-064, September, 2016

Available online http://www.e3journals.org

ISSN: 2276-9897 (C) E3 Journals 2016

DOI: http://dx.doi.org/10.18685/EJARD(6)3_EJARD-15-020

\title{
Changing Cropping Pattern around the Urban Centre: Analyzing the Role of Consumption Pattern of the People
}

\author{
Ghuncha Firdaus \\ Post-Doctoral Fellow, Madras Institute of Development Studies, Chennai; Phone No: 91-9884266599; \\ Email: g.firdausamu@gmail.com
}

Accepted 28 July, 2016

\begin{abstract}
Cropping pattern in developing countries has been undergoing a major transformation from cereals to noncereals cash crops, but, there is dearth of study evaluating cause and effect relationship of this phenomena. The objectives of the present study were to analyze the consumption pattern of major food items and its impact on cropping patterns in India as a whole and in the National Capital Territory (NCT) of Delhi particularly. The analysis depicts that cereal consumption/person/day in the country were declined by $11.6 \%$, whereas the consumption of eggs, vegetables and fruits were increased by $80.41 \%, 41.58 \%$, and $39.13 \%$ respectively during 1993-2013. The impact of changing consumption behaviour on cropping pattern was depicted by increasing areas under fruits (14.4\%), vegetables $(15.37 \%)$, spices $(16.9 \%)$ and plantation crops $(13.16 \%)$. A similar trend was observed in the case of NCT of Delhi. Information collected from 896 farming households revealed that vegetables $(28.38 \%)$, potatoes $(25.32 \%)$ and cereals $(23.9 \%)$ were the prime crops in the study area. Increasing demand of non-cereal crops in the city markets, $(p<0.000)$, in the local market, and in commercial establishments $(p<0.05)$ were determined the cropping pattern. With changing consumption pattern, more and more agricultural land may be devoted to non-grain crops. Integrated planning for land allocation between grain and non-grain crops is needed for sustainable agriculture development.
\end{abstract}

Key words: Delhi, consumption pattern, cropping pattern, food grain, non-cereals

\section{INTRODUCTION}

Cropping pattern refers to the proportion of area under different crops at a point of time. A change in cropping pattern thus implies a change in the proportion of area under different crops during two or more points of time. It is, however, dynamic as no cropping pattern can be good for all times to come, and differs from macro to micro regions, both in space and time. Cropping patterns of a region are mainly controlled by agro-ecological setting for the nourishment and appropriateness of a crop or a combination of crops.

The decisions with respect to choice of crops and cropping pattern are further narrowed down under the influence of several other factors related to infrastructural facilities (irrigation, transportion, storage, trade and marketing, post-harvest handling and processing), technological factors (improved varieties, cultural requirements, mechanization, plant protection measures, access to information), socio-economic factors ( financial resource base, land ownership, size and type of land holding, household needs of food, fodder, fuel, fibre and finance, and labour availability), and political factors (government plans and policies) (Ratheesh, 2014; Mohammed, 2007; Matsuda, 1994; Vaidyanathan, 1987). Nevertheless, at farmers' level, monetary benefits mainly act as guiding principles while opting for a particular crop or a cropping pattern.

Net return per acre of crops influences the acreage under crops, mainly in two ways. Firstly, the variations in intercrop price disparities lead to shifts in acreage allocation between the high and low remunerative crops. 
Secondly, to maintain a stable level of prices for a considerable period of time from a crop or a combination of crops leads to shifts in acreage allocation in favour of crops less susceptible to price fluctuation despite of being less remunerative. To be more specific, the cropping pattern is governed by law of comparative advantage in relation to agro-climatic conditions (Bowman and Zilberman, 2013; Vyas, 1996).

Agriculture in India has a predominant position, provides a livelihood for two-thirds of the population, gives employment to around $52 \%$ of the workforce, and accounted for $13.7 \%$ of the gross domestic product in 2013-14 (Agricultural statistics, 2015). But, from the last few decades, agriculture in the country has been undergoing a major transformation, driven by the same factors shaping the nation's current demographic scenario i.e. Urbanization. By and large, India is still a rural country; however, a process of rapid urbanization is already making strides in the form of growth of big cities and urban agglomerations. Like the other countries around the world, increasing urbanization in the country is inducing major changes in demand for agricultural products, both from increases in urban populations and, from changes in their food preference, which in turn tend to increase demand for high quality, more diverse and year round non-grain crops and animal products (Zhai et al., 2009; Chatterjee et al., 2006; Huang and David, 2003; Rao, 2000; Popkin, 1999).

Numerous studies demonstrate an emerging shift in food consumption pattern from food grain to non grain crops and animal products in the country (Gupta \& Mishra 2014; Ramesh \& Pradhan 2006; Kumar, 1998; Kumar and Mathur, 1997; Huang and David, 1993; Radhakrishna and Ravi, 1992). Therefore, it is expected that with increasing urbanization, cereal consumption in the country will tend to decrease and non-cereal and animal products will likely to increase. According to a research report the composition of calorie supply from grain, non-grain and animal products is expected to increase from $63 \%, 29 \%$ and $8 \%$ in 2000 , to $55 \%, 33 \%$ and $12 \%$ by 2025 , and $48 \%, 36 \%$ and $16 \%$ by 2050 , respectively (Amarasinghe et.al., 2007). The changing consumption patterns have had, and will continue to bring major changes in how agricultural demands are met, and what is produced where and how, that will adversely affect global food supply, balance in eco- system, biodiversity and quality of land and water resources. Therefore, it is very imperative to analyse the changing cropping pattern in the country with particular reference to food preference of the people. It was hypothesized that urbanization leads to change in the consumption behaviour of the people, which in turn determines the cropping pattern at the macro as well as micro levels..

Considering this point, the National Capital Territory (NCT) of Delhi was selected for micro level study (Figure 1). The NCT of Delhi was considered the ideal subject for the present study because the ever increasing urbanisation has been immensely transformed the agricultural activities in the region (Ghuncha and Ahmad, 2011). Further, the traditional agricultural practice has also been replaced by high value commercial horticulture and other high value added agricultural activities (Economic Survey of Delhi, 2014-15). Apart from it, having the highest percentage of urban population (i.e., $97.5 \%$ ) in India, it represents both modern and traditional features of the Indian urban system in particular and of developing world in general.

The present study was designed to examine the impact of consumption pattern on cropping pattern while identifying the factors contributing most to this association. The study discussed the issues as follows: firstly, it discusses the consumption pattern of the people, both in rural and urban population at the national level. Secondly, it analyses the trend of consumption of major food items in both urban and rural areas of the NCT of Delhi. Thirdly, the implication of changing consumption pattern of the people on the cropping pattern was evaluated. Finally, it was tried to assess the extent to which this association is determined by the specific determinants of the social environment with particular reference to the NCT of Delhi.

\section{Data sources}

The study is based on both primary and secondary sources of data, and has an exploratory design. The primary data were collected through field surveys, whereas the secondary data were obtained from government and quasi-government agencies and institutions through published and unpublished reports, records and literature. Accounts of the secondary sources of data include: National Sample Survey's published reports $\left(50,55,61,66^{\text {th }}\right.$ round's reports), the Municipal Corporation of Delhi (MCD), and Department of Economics and Statistics of Government of NCT of Delhi.

Primary data were obtained from field survey conducted during March-April 2014 with the help of a structured questionnaire. After reviewing secondary data, a list of villages located in seven districts of NCT of Delhi was prepared, and from each district $5 \%$ of the total villages were selected for intensive study. For the selection of villages a purposive random sampling method was applied. In total, 11 villages were selected on the basis of their agricultural characteristics, including the type of agricultural activities, infrastructural facilities and farming characteristics. From these selected villages, each fifth farming household was chosen for an interview. The study was limited to the head of the household because they have a primary role in the decision-making process of agricultural activities. In all, 849 head of household were interviewed.

The questionnaire covered the following aspects: farmers' socio-economic characteristics, area under 


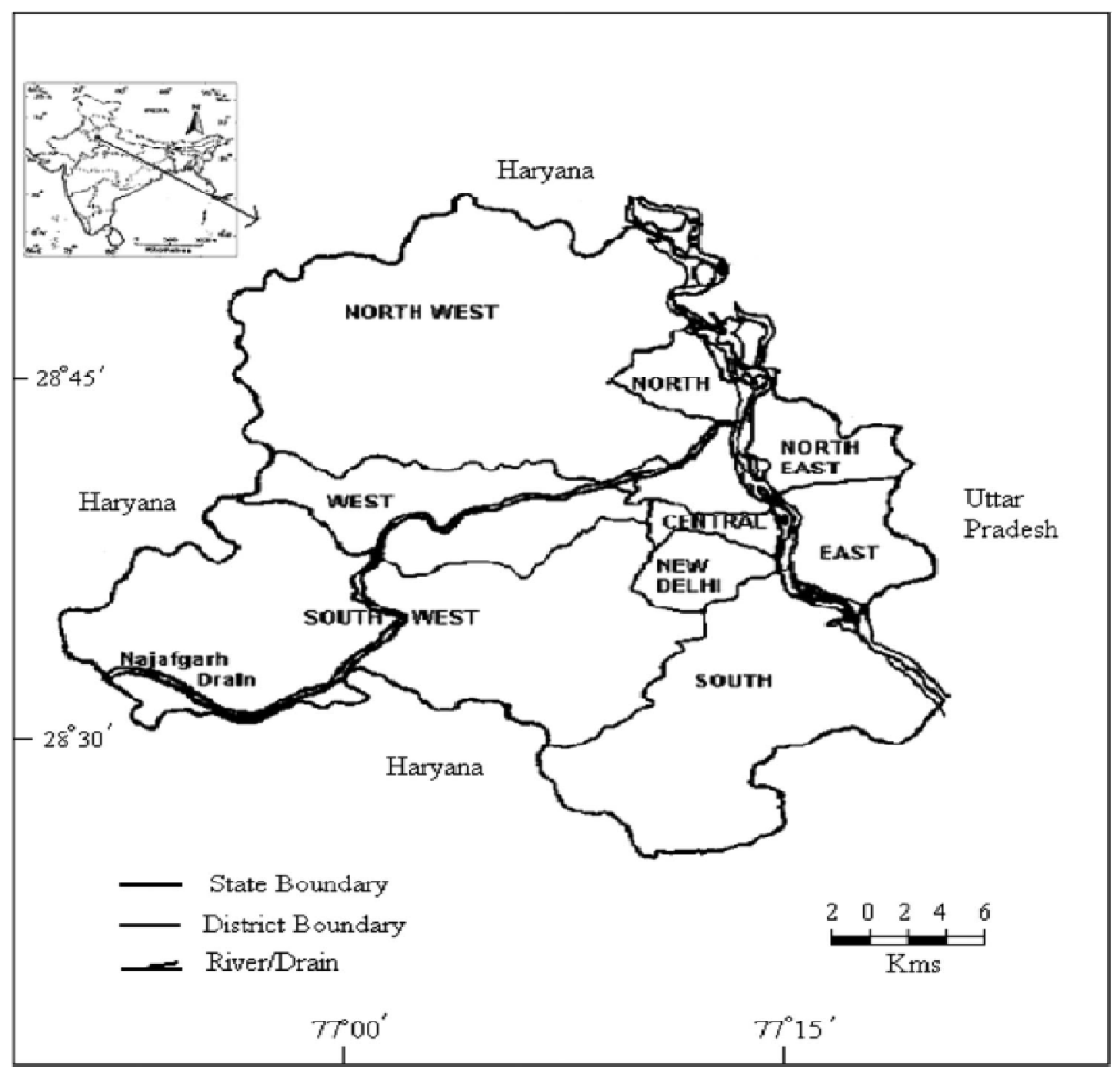

Figure 1: Location Map of NCT of Delhi

different crops, and changes in the cropping patterns during the last ten years. Apart from household surveys, key informants such as farmers' groups were consulted with the aim of obtaining information about the changing nature of agricultural activities in the study area. A field survey included transects across the farmland to observe cropping patterns, and also to verify the information collected through group discussions and household surveys.

\section{METHODOLOGY}

The collected data were organized, classified and analyzed with suitable statistical techniques. Secondary data regarding consumption of major food items in India, and in the NCT of Delhi, were presented through simple cartographic techniques, i.e. diagrammatic method, to develop a more detailed understanding of temporal variation in the consumption pattern. Cropping pattern data for different years were arranged through simple tabulation method to get detailed information about area allocation to different crops. Primary information farmers were categorized into four categories on the basis of their size of landholding i.e. marginal $(<1$ hectare.), small (1-2 hect.), medium (2.1-3 hect.) and large (3.1-4 hect.), and then, the percentage of area under different crops (i.e. cereals, pulses, potatoes, vegetables, flowers, fruits) were calculated for each category of farmers. To identify the factors controlling farmers' decision making process about cropping pattern, various determinants were identified and analysed through a multiple regression method.

$D$ (index) $=\beta_{0}+\beta_{1} X_{1}+\beta_{2} X_{2}+++\beta_{n} X_{n}$

Where,

$\mathrm{D}($ index $)=$ Determinants of cropping pattern 


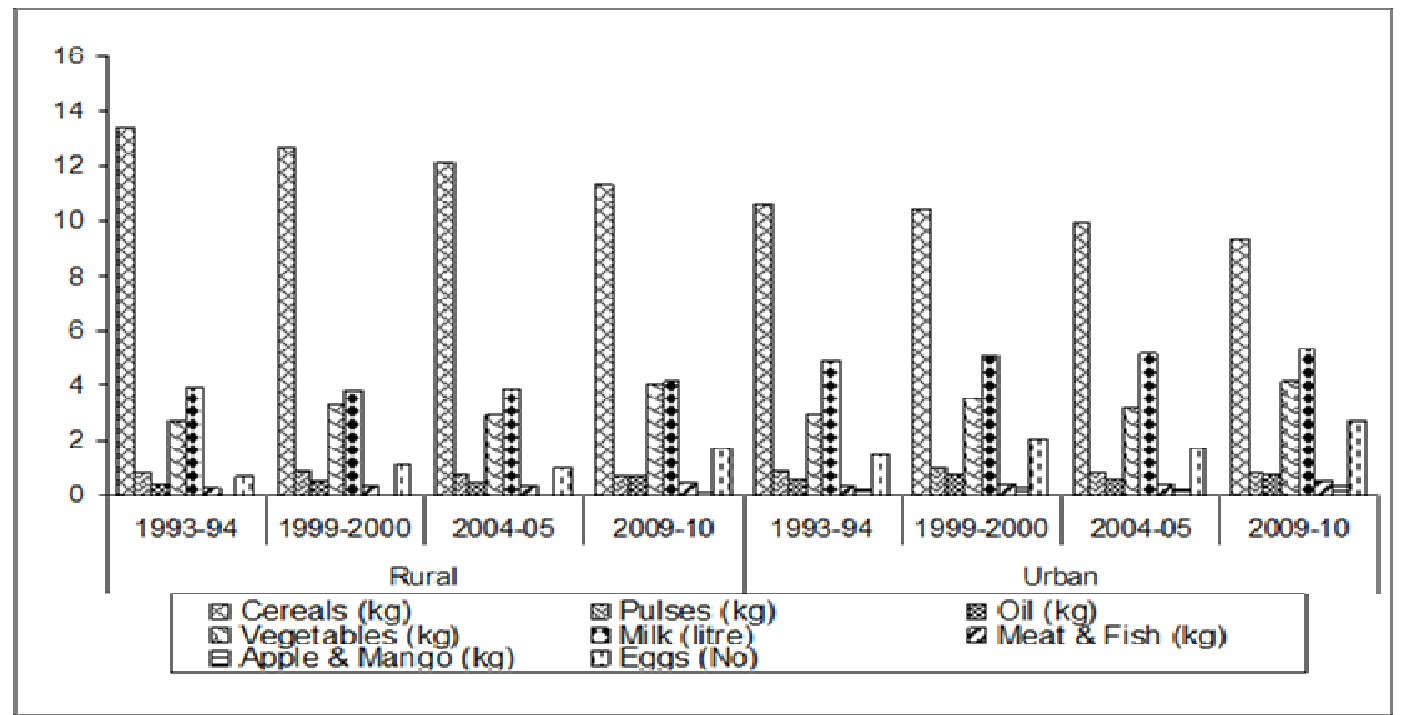

Figure 2: Per capita per month consumption of major food items in India during $1993-2010$

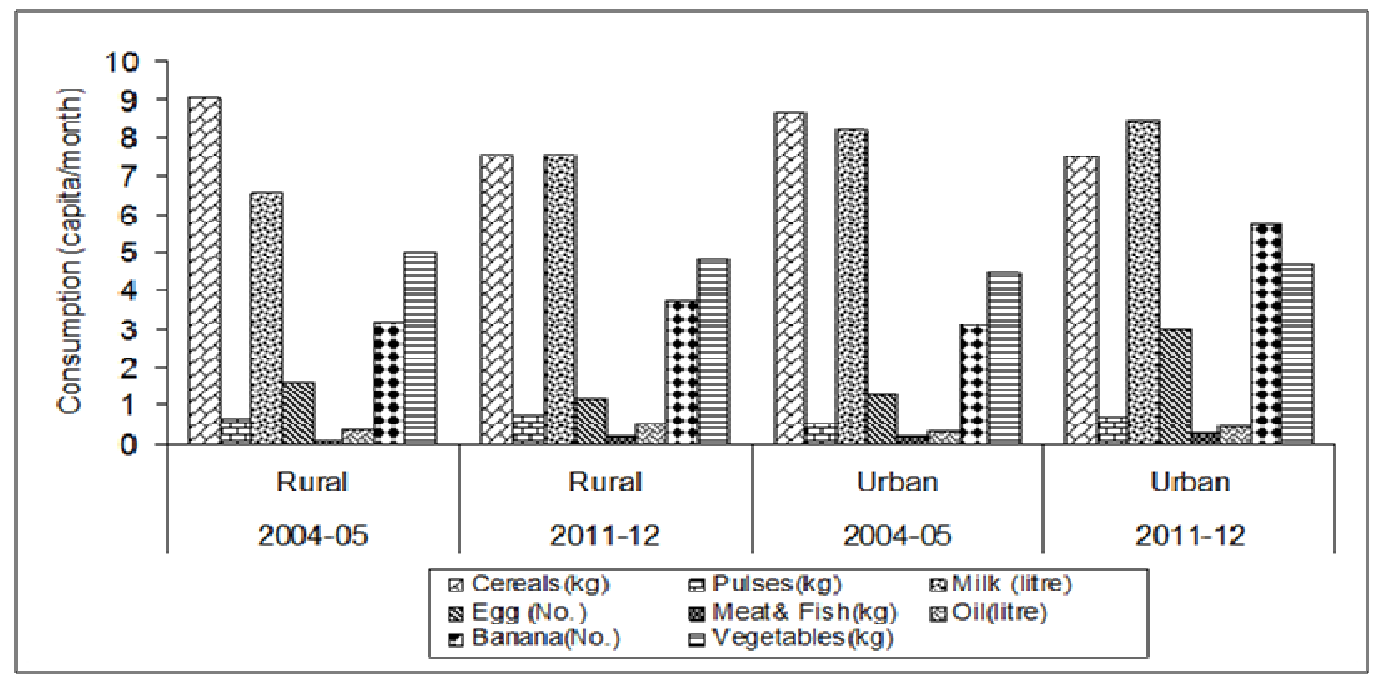

Figure 3: Per capita per month consumption of major food items in Delhi

$\beta_{0}=$ Intercept

$\beta_{1}-\beta_{6}=$ Coefficients of the explanatory variables

The dependent variable, i.e., cropping pattern, hypothesized to be influenced by six independent factors, i.e. increasing demand of a particular crop from local market $\left(X_{1}\right)$, from city market $\left(X_{2}\right)$, from commercial establishments $\left(X_{3}\right)$, from surrounding states $\left(X_{4}\right)$, for export to other states $\left(X_{5}\right)$, and increasing demand from the social institution like orphanages, ashrams, hostels $\left(\mathrm{X}_{6}\right)$. These independent factors were identified on the basis of the percentage of farmers who considered these factors as significant reasons of changing cropping pattern in the study area.

\section{RESULTS AND DISCUSSION}

\section{Consumption Pattern of Major Food Items in India}

Figure 2 shows percentage break-up of monthly per capita consumption of major food items including 'all cereals', 'pulses', 'edible oil', 'vegetables', 'milk', 'meat \& fish', 'eggs', and 'fruits' in urban and rural India spanning over the period of twenty years (1993-94 -2013-14). In general, the consumption of cereals shows a declining trend both in rural and urban areas. The per capita consumption of cereals in urban areas was declined from $10.6 \mathrm{~kg}$ to $9.94 \mathrm{~kg}$ per month, whereas in rural areas, it 
was declined from $13.4 \mathrm{~kg}$ to $11.35 \mathrm{~kg}$ per month during the observational period. Like cereals, a declining trend in the consumption of pulses was also observed. It declined from $0.86 \mathrm{~kg}$ to $0.79 \mathrm{~kg} / \mathrm{capita} / \mathrm{month}$ in urban areas, and from $0.76 \mathrm{~kg}$ to $0.65 \mathrm{~kg} / \mathrm{capita} / \mathrm{month}$ in rural areas over the period of twenty years.

The consumption of edible oil shows an increasing trend in both urban and rural areas, but its consumption was found to be $12.5 \%$ higher in urban areas than the rural areas. The consumption of vegetables shows an increasing trend with less pronounced rural-urban intake gap. A prominent spatial and temporal disparity were observed in milk consumption. Despite showing an increasing trend in rural areas, the consumption of milk in urban areas was found to be higher by $30 \%$ than the rural areas. The consumption was increased from 4.89 to 5.36 liter/capita/month in urban areas and from 3.94 to 4.12 liter /capita /month in rural areas (1993-2013). Following this trend, the consumption of meat and fish also appears to be higher in urban areas i.e. $0.34-0.51 \mathrm{~kg} / \mathrm{capita} / \mathrm{month}$ than the rural areas (0.26-0.44 $\mathrm{kg}$ capita/month). The consumption of egg shows wide rural-urban intake gap $(54.33 \%)$. In urban areas the consumption rate was 2.67/capita/month while in rural areas, it was 1.73/capita/month. Highest rural-urban intake gap was observed in the consumption of fruits, i.e. $540 \%$, and its consumption has been consistently increasing over time, especially in urban India.

The present study found a wide rural-urban disparity in the consumption pattern of major food items in the country. Traditionally, cereals have been dominating the vegetables centered diet of the Indian people, where rice is the main food grain in the south and the east, followed by wheat in the east and coarse cereals in the south. Wheat is the principal food grain in the north and the west, followed by rice and other coarse cereals in the west, and by rice in the north. However, the present data of national consumption pattern indicate different trends, i.e. a considerable shift from cereal consumption to noncereals food items mainly vegetables, milk, eggs, meat, fish and fruits. The present finding is in conformity with earlier studies conducted elsewhere (Delgado et al., 2005; Rosegrant et al., 2001; Bansil, 1999; Bhalla et al., 1999; Rao, 2000; Kumar, 1998; Kumar and Mathur, 1997; Radhakrishna and Ravi, 1992).

These emerging shifts in the consumption pattern in the country from grain to non-grain products may be attributed to urbanization, increasing income and changing standard of living. It is because of the fact that low income people increase their nutritional intake through easily accessible crops, such as cereals and pulses, but, as income and access to other food increase, people diversify food habits and consume more non-grain crops and animal products (Radhakrishna and Ravi, 1992). A substantial changes in the consumption pattern especially a trend of declining cereal intake and increase of consumption of other food items which has often been explained as an outcome of economic growth is found in numerous recent studies (Ali 2007; Atibudhi 2006; Giri 2006; Golait and Pradhan 2006; Nasurudeen et al. 2006; Radhakrishna 2006; Singh et al. 2006; Viswanathan 2001; Shariff and Mallick 1999; Radhakrishna and Reddy 2004).

\section{Consumption Pattern of Major Food Items in the NCT of Delhi}

Concerning to the consumption pattern of major food items in the rural and urban areas of NCT of Delhi, a shift in the patterns of nutritional intake from food grains to non-grain crops and animal products and a declining magnitude and share of calorie from cereals was observed. The consumption of cereals was found to be comparatively lower in urban areas accounting for 7.51 $\mathrm{kg} / \mathrm{capita} / \mathrm{month}$, whereas in rural areas, it was around $7.55 \mathrm{~kg} /$ capita/month during 2011-12 as compared to $8.64 \mathrm{~kg} /$ capita/month and $9.02 \mathrm{~kg} /$ capita/month respectively during 2004-05.

A fall of $15 \%$ in cereal consumption was observed in urban areas during the period of study. Pulses were showing an increasing consumption in both rural and urban areas. But, it had less consumption in urban areas than the rural areas (11.14\%). Following this increasing trend, the per capita consumption of oil also rose from $0.33 \mathrm{gm} /$ capita/ month to $0.48 \mathrm{gm} /$ capita/ month in urban areas, and from $0.36 \mathrm{gm}$ to $0.53 \mathrm{gm} /$ capita/ month in rural areas. Monthly per capita consumption of vegetables was observed to be increased by nearly $5 \%$ in urban areas; while it decreased by $3.8 \%$ in rural areas. The consumption of milk shows an increasing trend in both urban and rural areas, but in urban areas the per capita consumption was higher (10.6\%) than the rural areas.

The disparity between urban and rural areas in consumption of meat and fish was more pronounced with $34.35 \%$ rural-urban intake gap. In urban areas the consumption rose from $0.17 \mathrm{~kg}$ to $0.29 \mathrm{~kg}$ per capita/month, recoded $40 \%$ increase over the period of seven years, whereas in rural areas it increased by $13.68 \%$. A prominent urban-rural disparity was observed in egg consumption. Among the urban residents the consumption of eggs shown a $56.38 \%$ increase as it rose from 1.3 to $3 /$ capita/month, but, it declined from 1.6-1.1/ capita/month in rural areas. The consumption of fruits shows an increasing trend both in urban and rural areas, but it was found to be higher in urban areas i.e. $5.7 /$ capita/month than the rural areas (3.7/capita/month), recorded $34.33 \%$ rural-urban intake gap.

The consumption pattern shows a similar trend at the micro-level, i.e., the NCT of Delhi. The data indicate that Delhi has been experiencing a shift in the patterns of nutritional intake from food grains to non-grain crops and animal products. The collective effect of urbanization, increase in per capita income and high standard of living 
Table 1: Total Area under Different Crops in India

\begin{tabular}{lccccc}
\hline Crops Category & $\mathbf{2 0 0 8 - 0 9}$ & $\mathbf{2 0 0 9 - 1 0}$ & $\mathbf{2 0 1 0 - 1 1}$ & $\mathbf{2 0 1 1 - 1 2}$ & $\mathbf{2 0 1 2 - 1 3}$ \\
\hline Food Grains (million hect.) & 122.83 & 121.33 & 126.67 & 123.93 & 120.16 \\
Pulses (million hect.) & 22.09 & 23.28 & 26.4 & 23.97 & 23.47 \\
Oilseeds (million hect.) & 27.56 & 25.96 & 27.22 & 26.31 & 26.53 \\
Nuts (000 hect.) & N.A. & N.A. & 138.4 & 173.9 & 144 \\
Fruits (000 hect.) & 6102.3 & 6323 & 6382.6 & 6705 & 6982 \\
Vegetables (000 hect.) & 7979 & 8011 & 8494.5 & 8989 & 9206 \\
Spices (000 hect.) & 2629.4 & 2463.7 & 2940.4 & 3212 & 3074 \\
Plantation (000 hect.) & 3217.3 & 3264.6 & 3305.7 & 3577 & 3641 \\
\hline
\end{tabular}

Source: Department of Agriculture and Cooperation

Table 2: Cropping pattern based on size of landholding in the NCT of Delhi

\begin{tabular}{|c|c|c|c|c|c|c|}
\hline \multirow[t]{2}{*}{ Categories } & \multicolumn{6}{|c|}{$\%$ of area under different crops } \\
\hline & Cereals & Pulses & Potatoes & Vegetables & Flowers & Fruits \\
\hline $\begin{array}{l}\text { Marginal } \\
<1 \text { hact }\end{array}$ & 3.25 & Nil & 19.23 & 41.12 & 23.07 & 13.6 \\
\hline $\begin{array}{l}\text { Small } \\
1-2 \text { hact }\end{array}$ & 24.08 & 6.02 & 19.39 & 34.11 & 8.69 & 7.69 \\
\hline $\begin{array}{l}\text { Medium } \\
2.1-3 \text { hact }\end{array}$ & 54.43 & Nil & 45.56 & Nil & Nil & Nil \\
\hline $\begin{array}{l}\text { Large } \\
3.1-4 \text { hact }\end{array}$ & 62.69 & Nil & 37.03 & Nil & Nil & Nil \\
\hline Total & 23.9 & 2.12 & 25.32 & 28.38 & 12.24 & 8.0 \\
\hline
\end{tabular}

Source: Based on Field Survey 2014; Note: Figure in parenthesis is \%

may be the reason behind the higher the consumption of all animal protein-supplying foods, fruits and vegetables in the NCT of Delhi. The present finding is in conformity with the study of Dyson and Hanchate (2000), based on consumption trend data between 1987-1988 and 19931994. He found a declining trend in per capita cereal consumption in all states except in Kerala and West Bengal. Another study based on 1960-1988 consumption data conducted by Huang \& David (1993) found a reducing demand for cereals in higher income Asian countries due to urbanization. Gupta and Mishra (2014) in their study of food consumption pattern in rural India also found a decline in cereal especially coarse cereal intake and an increasing trend in the consumption of other food items (fruits, vegetables, meat products) which vary across different socio-economic groups.

\section{Changing Cropping Pattern in India}

Changing consumption patterns are worth considering changes at household level which is determining the agricultural system of the country, mainly in the form of relative area allocation under the major crop groups. Table 1 shows areas under different crops during 2008-2013. The area under food grains was declined by $-2.17 \%$ from 122.83 to 120.6 million hectares during the period of observation.
Area under pulses depicts fluctuating trend, i.e. sometimes upward and sometimes downward. A downward trend was observed in the area of oilseed, it declined from 27.56 to 26.53 million hectares over the period of six years. The area under fruit cultivation was increased by $14.4 \%$ during 200813. Similarly, the area under vegetable was also increased by $15.3 \%$, from 7979 to 9206 thousand hectares. The area under spices was recorded the highest growth rate, it increased by almost $17 \%$ during the observational period. Plantation crop acreage also appeared to increase by $13 \%$ over the same period of study. In the wake of this trend, two types of significant changes has been observed in the cropping pattern of the country; firstly, the relative area allocation of cereal crops have been decreasing continuously, and secondly, fruits, vegetables and spices have been gaining considerable importance in area allocation. The finding of the present study is in conformity with earlier studies which observed a shift in the Indian agricultural system from food grain crops to commercial crops (Ghosh, 2011).

\section{Changing Cropping Pattern in the NCT of Delhi}

The changing consumption pattern has also been influencing the cropping pattern in the NCT of Delhi (Table 2). 
Table 3: Factors affecting cropping pattern in the National Capital Territory of Delhi

\begin{tabular}{lccc}
\hline Variables & Co-efficient & t-state & Sig. \\
\hline Intercept & 6.647 & 16.75 & 0.001 \\
Demand in local market & 0.046 & 6.33 & 0.028 \\
Demand in city market & 1.074 & 40.57 & 0.000 \\
Demand from Commercial establishment & 0.399 & 13.84 & 0.022 \\
Demand from surrounding states & 0.576 & 13.71 & 0.036 \\
Demand for exports & 0.399 & 13.84 & 0.047 \\
Demand from social institution & 0.124 & 2.80 & 0.082 \\
\hline
\end{tabular}

the cropping pattern practiced by the different size of farmers in the NCT of Delhi. In general, area under vegetation shows largest share i.e. $28.38 \%$ among all crops followed by potatoes $(25.32 \%)$, cereals $(23.9 \%)$ flowers (12.24\%) and fruits (8\%). Vegetables were mainly cultivated by very small and small farmers, devoted $41.12 \%$ and $34.11 \%$ of the total area under this crop respectively. Next in importance were potatoes, cultivated by all categories of farmers. Nearly $46 \%$ and $37 \%$ of the total area were devoted to the potato cultivation by medium and large farmers respectively. Cereals were found to be third significant crop mainly cultivated by large farmers.

Fruits and flower cultivation was gaining momentum, and were mainly cultivated by very small and small farmers. In general, the cropping pattern in the study area shows more inclination towards horticulture crops, especially vegetables, seasonal fruits and flowers rather than food grain crops as observed in other states of the country (Mahesh, 1999).

\section{Dterminanats of Changing Cropping Pattern in the NCT of Delhi}

Table 3 shows the determinants of changing cropping patterns in NCT of Delhi. Increasing demand in city market appeared to be the most significant factor $(p=0.000)$ influencing the cropping pattern. The coefficients of increasing demand from a commercial establishment and local market positively influenced the cropping pattern, and were significant at $95 \%$ confidence level. Demand for exports to other states and from social institutions was appeared to be insignificant determinants $(p=>0.05)$ of the changing cropping pattern in the study area.

The NCT of Delhi, being overwhelming urban, where 97.50 per cent of the total population lives in urban areas and remaining 2.5 percent in rural areas (2011 Census) provides a large market for horticulture crops. There is a great demand for vegetables, fruits, flowers throughout the year. Consequently, the returns from commercial horticulture and other high value added agricultural activities are higher compared to the traditional crops. Therefore, farmers are taking-up vegetables, floriculture production, mushroom cultivation and seasonal fruit cultivation (Firdaus \& Ahmad, 2011) instead of traditional crops.

Apart from the increasing domestic consumption, there is an increasing demand for horticulture crops from commercial sectors including hotels, restaurant and other food outlets. As the city of Delhi is the hub of social, political and economic opportunities, there is large concentration of hotels and restaurants to meet the increasing demand of food. Further, the increasing income levels of the residents accompanied by exposure to the global 'urban' eating pattern have also resulted in increasing consumption of many Western-style food items. The decreasing demand of traditional food items is inducing major changes in cropping pattern on surrounding agricultural land to meet the requirement of urban society. Our finding is in agreement with earlier studies conducted elsewhere (Satterthwaite, 2010; de Haen et al., 2003; Popkin, 2001).

\section{CONCLUSION}

The present study confirms a close association between urbanization and consumption behavior of the people and its impact on cropping pattern at the macro as well as micro levels. Presently, the impact of changing consumption patterns on agricultural activities is mainly taking place in and around the urban areas, and expected to continue with increasing urbanization in the near future. As per census 2011, there are thirty five million plus cities in India, accommodating 108.29 million people. If the present trends of consumption pattern will continue, a major portion of agricultural land will be required for non-grain, and fodder crops, that will lead to food insecurity, and degradation of land and water resources, ending into social, economic, environmental and political imbalances around the world. Therefore, the effects of urbanization may need to be taken into consideration in forecasting future food demand by taking into consideration the underlying structural shifts in consumption pattern that may help in developing proper agricultural land use policies. 


\section{Contribution of the Study}

This is the first study which highlighted the changing cropping pattern around the urban center in response of the changing consumption behavior of the people in India. Our study adds to the growing body of literature examining impact of social factors on agriculture, and does generate some provocative insights about the associations between the factor operating at household level, i.e. the consumption pattern of the people, and its impact on cropping pattern at the macro as well as micro levels. Therefore, the present study can be utilized to formulate comprehensive planning and policies, especially on agriculture, rural and urban sectors within the framework of economic viability, social desirability and environmental sustainability that will be applied at local, regional and national levels.

Limitation: Like the other studies our study is not free from limitations. In measuring the changing cropping pattern, our focus of analysis was only one attribute i.e. consumption pattern. The association between these two attributes might also be mediated by socio-economic condition, political factors, culture and tradition, modern infrastructural facilities, and institutional factors which were not included in this analysis. The result could be more comprehensible if these factors were included in the analysis. Accordingly, future studies should not rely on any single indicator, but rather, the complex pathways between socio-economic indicators and their implication on the whole agricultural system of the country.

\section{ACKNOWLEDGEMENT}

I express my deepest sense of gratitude to Prof. D Jayaraj, Madras Institute of Development Studies, Chennai, for his excellent guidance, constructive criticism and support during the preparation of the manuscript. I am thankful to the UGC, Govt. of India, New Delhi, India, for the financial support in the form of Postdoctoral Fellowship (15-82/12(SA-II).

\section{REFERENCES}

Ali J (2007). Structural Changes in Food Consumption and Nutritional Intake from Livestock Products in India. South Asia Res. 27(2): 137-151.

Atibudhi HN (2006). A Comparative Analysis of Food Consumption and Monthly Per Capita Expenditure of Orissa vis-a-vis All India Level, Indian J. Agric. Econ. 61: 3.

Arora VPS, Sharma JS (1981). Optimal allocation of fertilizer, nutrients among different regions of U.P and its impact on cropping patterns and production levels. Agric. Situation in India, 36, 1, 3.

Agricultural statistics (2013). Ministry of Agriculture, Government of India, New Delhi, 4.

Bazaz NH, Haq I (2013). Crop diversification in Jammu and
Kashmir: pace, pattern and Determinants. J. Humanities and Soc. Sci. 11(5):1-7

Chatterjee S, Rae A, Ray R (2006). Food consumption, trade reforms and trade patterns in contemporary India: How do Australia and NZ fit in? Working Paper 2/06. New Zealand: Centre for Applied Economics and Policy Studies, Massey University.

de Haen H, Stamoulis K, Shetty P, Pingali P (2003). The world food economy in the twenty-first century: challenges for international co-operation. Develop. Pol. Rev. 21: 683-696. (doi:10.1111/j.1467-8659.2003. 00232.x)

Dyson T, Hanchate A (2000). India's demographic and food prospects: State level analysis. Econ. Political Weekly, 11: 4021-4036.

Dantwala, ML (1986). Prices and cropping Pattern, Econ. Political Weekly, 21: 16, 694.

Economic survey of Delhi (2012-13). Agric. Rural Developm. Chapt.10: 134.

Firdaus G, Ahmad A (2011). Impact analysis of urbanization on rural livelihood - an empirical study of an urban centre of Delhi, India, Intl. J. Urban Sci. 15(3): 147-160

Giri A K (2006). Cereal Consumption over Time in the Country and across the States, Indian J. Agric. Econ. 61: 3.

Ghosh BK (2011). Determinants of the changes in cropping pattern in India: 1970-71 to 2006-07, Bangladesh Develop. Studies, XXXIV(2):109-120.

Gupta AK (1963). Inter-State differences in cropping pattern and productivity, Indian J. Agric. Econ. 18(1): 24.

Gupta A, Mishra KD (2014). Food consumption pattern in rural India: a regional perspective. J. Econ. Soc. Develop. X(1): 116

Golait R, Pradhan NC (2006). Changing Food Consumption Pattern in Rural India: Implication on food and Nutrition security, Indian Journal of Agricultural Economics, 61,3

Huang J, David CC (1993). Demand for cereal grains in Asia: The effect of urbanization. Agric. Econ. 8(2): 107-124.

Joglekar NM (1963). Study of crop pattern on an urban fringe, Indian J. Agric. Econ. 18(1): 74.

Kumar P (1998). Food demand and supply projection for India. Agricultural Economics Policy Paper 98-01, New Delhi: Indian Agricultural Research Institute.

Kumar P, Mathur VC(1997). Agriculture in future: demand and supply prospective. In: Agricultural development paradigm for the ninth plan under new economic development, ed. B. M. Desai. New Delhi, India: Oxford and IBH Publishing.

Kumar DU (2003). Changing cropping pattern system in theory and practice: an economic insight into the agrarian West Bengal, Indian J. Agric. Econ. 58(1): 64-83.

Krishna R (1963). The optimality of land allocation- a case study of Punjab, Indian J. Agric. Econ. 18(1): 54.

Mahesh R (1999). Causes and consequences of change in cropping pattern: a location-specific study, Discussion Paper No. 11, Kerala Research Programme on Local Level Development, Centre for Development Studies, Thiruvananthapuram, 1-56.

Mandal GC, Ghosh SK (1963) Some aspects of the economics of cropping pattern: a case study of condition in the district of Manghyr, Bihar, Indian J. Agric. Econ. 18(1): 74.

Mohammed A, Muneer A, Siddiqui SH (2007). Fifty years of Indian agriculture.New Delhi, Concept Publication Company.

Matsuda T (1994). Irrigation, infrastructure and diversification of Paddy land use. Japanese J. Farm Manage. 31: 78-79. 
Narayanamoorthy A (2007). Deceleration in agricultural growth technology fatigue orpolicy fatigue? Econ. Political Weekly, 42(25): 2376-2379.

Nasurudeen P, Kuruvila A, Sendhil R, Chandresekar V (2006). The Dynamics and Inequality of Nutrient Consumption in India, Indian J. Agric. Econ. 61(3): 362-373.

Popkin BM (2001). The nutrition transition and obesity in the developing world. J. Nutri. 131: S871-S873.

Narain D (1977). Growth of productivity in Indian agriculture, Indian J. Agric. Econ. 32(1): 1- 44.

Popkin BM (1999). Urbanization, lifestyle changes and the nutrition transition. World Dev. 27: 1905-1916. (doi:10.1016/S0305-750X(99)00094-7)

Popkin BM (2001). Nutrition in transition: The changing global nutrition challenge. Asia Pacific J. Clinical Nutrition 10 (Suppl. 1): S13-S18.

Radhakrishna R, Ravi C (1992). Effects of growth, relative price and performances of food and nutrition. The Indian Econ. Rev. 27: 303-23.

Radhakrishna R, Reddy V (2004). Food Security and Nutrition: Vision 2020, [Online] Available at:planningcommission.nic.in/reports/.../bkpap2020/16_Bg202 0.pdf.

Radhakrishna R (2006). Food Consumption and Nutritional Status in India: Emerging Trends and Perspectives, Working Paper, November, Indira Gandhi Institute of Development Research, Mumbai.

Rao CHH (2000). Declining demand for food grains in rural India: census and implications. Economic and Political Weekly (January 22).

Ramalingam C (1963). Some economic aspects of cropping pattern, Indian J. Agric. Econ. 18(1):161.

Ratheesh MP (2014). Making of a globalizes cropping patternA study of cropping pattern change in wandoor block, Kerala, Research Forum: Intl. J. Soc. Sci. 2(2): 19-26.

Satterthwaite D, McGranahan G, Tacoli C (2010). Urbanization and its implications for food and farming, Phil. Trans. R. Soc. B 2010 365, doi: 10.1098/rstb.2010.0136

Savale RS (1966). Intensive development approach to agricultural development: role of irrigation and cropping pattern in agricultural development, Indian Journal of Agricultural Economics, 21, 4, 96.

Sharma AC, Kahlon AS (1972). Impact of technology development on the normative shifts in cropping pattern, Indian J. Agric. Econ. 27(4): 158.

Shariff A, Mallick A C (1999). Dynamics of Food Intake and Nutrition by Expenditure Class in India, Econ. Political Weekly, 34, 27,1790-1800.

Sinha AK (1978). Impact of lift irrigation on cropping pattern and yields: based on a five- village survey in Bhiwani, Haryana, Indian J. Agric. Econ. 33(1): 77.

Singh H (1963). Factors for shifts in groundnut acreage, Indian J. Agric. Econ. 18(1): 24.

Singh RK, Vishwakarma A, Singh PK (2006). Food Security and Policy Perspective in India, Indian J. Agric. Econ. 61: 3.

United Nations (2014). Population Division of the Department of Economic and Social Affairs of the United Nations Secretariat, World Population Prospects: The 2011 Revision. United Nations Population Division (2010). World Urbanization Prospects: The 2009 Revision (POP/DB/WUP/Rev.2007) United Nations Department of Economic and Social Affairs, New York.

Vaidyanathan A (1987). Agricultural development in eastern India. Economic and Political Weekly, 22, 52, December 26.

Vivekananda M, Sathyapriya VS (1994). Karnataka's changing cropping pattern. Agric. Situat. India, 49(6): 441.

Viswanathan B (2001) Structural breaks in consumption patterns: India 1952-1991, Appl. Econ. 33(9): 1187-1200.

Vyas VS (1996). Diversification in agriculture: concept, rationale and approaches. Indian J. Agric. Econ. 51 (4): 636-643.

Zhai F, Wang H, Du S, He Y, Wang Z, Ge K, Popkin BM (2009). Prospective study on nutrition transition in China. Nutrition Review. 67 (Suppl. 1), 56-61. 